\title{
Helium-oxygen reduces the production of carbon dioxide during weaning from mechanical ventilation
}

\author{
Gordon Flynn ${ }^{1,3^{*}}$, Gerlinde Mandersloot ${ }^{1}$, Marie Healy ${ }^{1}$, Mark Saville ${ }^{1}$, Daniel F McAuley ${ }^{2}$
}

\begin{abstract}
Background: Prolonged weaning from mechanical ventilation has a major impact on ICU bed occupancy and patient outcome, and has significant cost implications.

There is evidence in patients around the period of extubation that helium-oxygen leads to a reduction in the work of breathing. Therefore breathing helium-oxygen during weaning may be a useful adjunct to facilitate weaning. We hypothesised that breathing helium-oxygen would reduce carbon dioxide production during the weaning phase of mechanical ventilation.

Materials/patients and methods: We performed a prospective randomised controlled single blinded cross-over trial on 19 adult intensive care patients without significant airways disease who fulfilled criteria for weaning with CPAP. Patients were randomised to helium-oxygen and air-oxygen delivered during a 2 hour period of CPAP ventilation. Carbon dioxide production $\left(\mathrm{VCO}_{2}\right)$ was measured using a near patient main stream infrared carbon dioxide sensor and fixed orifice pneumotachograph.
\end{abstract}

Results: Compared to air-oxygen, helium-oxygen significantly decreased $\mathrm{VCO}_{2}$ production at the end of the 2 hour period of CPAP ventilation; there was a mean difference in $\mathrm{CO}_{2}$ production of $48.9 \mathrm{ml} / \mathrm{min}(95 \% \mathrm{Cl} 18.7-79.2$ $p=0.003)$ between the groups. There were no significant differences in other respiratory and haemodynamic parameters.

Conclusion: This study shows that breathing a helium-oxygen mixture during weaning reduces carbon dioxide production. This physiological study supports the need for a clinical trial of helium-oxygen mixture during the weaning phase of mechanical ventilation with duration of weaning as the primary outcome.

Trial registration: ISRCTN56470948

\section{Introduction}

Weaning from mechanical ventilation is estimated to account for up to $40 \%$ of the total duration of ventilatory support [1]. The process of weaning patients therefore has a major impact on ICU bed occupancy with significant cost implication [2]. Strategies to facilitate weaning have a major potential to reduce use of healthcare resources $[3,4]$.

Helium is an inert gas and prolonged administration to animals has demonstrated no adverse effects [5].

\footnotetext{
* Correspondence: Gordon.Flynn@sesiahs.health.nsw.gov.au

'Intensive Care Unit, Royal London Hospital, Whitechapel, London, E1 1BB, UK

Full list of author information is available at the end of the article
}

Helium has a lower density and higher viscosity compared with oxygen and nitrogen. Breathing helium leads to a decreased resistance in gas flow, a change from turbulent to laminar flow patterns [6] and a reduction in the work of breathing. However a change from turbulent to laminar flow patterns is unnecessary for the reduction in the work of breathing which can occur under fully turbulent flow [7].

Helium-oxygen has been used in clinical situations where upper or lower airways obstruction or disease leads to an increased resistance to flow. Although there are many case reports of successful use of helium-oxygen in these conditions, to date no studies have conclusively

\section{Biomed Central}

C 2010 Flynn et al; licensee BioMed Central Ltd. This is an Open Access article distributed under the terms of the Creative Commons Attribution License (http://creativecommons.org/licenses/by/2.0), which permits unrestricted use, distribution, and reproduction in any medium, provided the original work is properly cited. 
demonstrated improved outcomes in these patient groups [8].

There are limited data regarding the use of heliumoxygen during weaning. Use of a helium-oxygen mixture during weaning with CPAP has been successfully used to improve respiratory distress and improve $\mathrm{PaO}_{2}$ after cardiovascular surgery in a small study in infants [9]. In addition, in ventilated patients with airflow obstruction, breathing helium-oxygen during a $\mathrm{T}$-piece breathing trial just prior to extubation resulted in a reduction in airway resistance and consequently a decrease in work of breathing [10].

The aim of this physiological study was to determine whether breathing a helium-oxygen mixture as compared with an air-oxygen mixture during the weaning phase of mechanical ventilation would reduce carbon dioxide production in patients without significant airways obstruction.

\section{Materials and methods}

We conducted a prospective single centre, randomised, single blinded, controlled, cross-over study in our 18 bed mixed medical-surgical ICU. Approval for the study was obtained from Research Ethics Committee and the Medicines and Health Regulatory Agency (MHRA). Eligible patients were ready for weaning to CPAP and had to meet the following inclusion criteria; the underlying cause of respiratory failure was improving, pressure support ventilation of less than $10 \mathrm{cmH}_{2} \mathrm{O}$, no continuous intravenous sedation or inotropes, $\mathrm{FiO}_{2}$ less than or equal to 0.4 and requiring less than $10 \mathrm{cmH}_{2} \mathrm{O}$ positive end expiratory pressure. Written informed consent from the patient or assent from their next of kin was obtained.

Respiratory parameters were measured using a near patient main stream infrared carbon dioxide sensor and fixed orifice pneumotachograph connected to a respiratory profile monitor $\left(\mathrm{CO}_{2} \mathrm{SMO}\right.$ Plus Respiratory Monitor, Novametrix Medical systems, Wallingford, CT, USA) and analysed using computer software (Analysis plus). The capnograph is barometric pressure compensated with an accuracy of $+/-2 \mathrm{mmHg}$ (for $0-40 \mathrm{mmHg}$ ) and $+/-5 \%$ of the reading (for $41-70 \mathrm{mmHg}$ ). The pneumotachograph is a disposable device using differential pressure with an overall accuracy of $+/-2 \%$. This device was calibrated for the specific fraction of inspired helium and oxygen on an individual patient basis according to the manufacturer's instructions. On initialisation the device performs a zero calibration. The accuracy of the infrared carbon dioxide sensor is further verified by using a calibration device for carbon dioxide. Furthermore a previous study showed the monitoring device remained stable and accurate over a 48 hour period of continuous monitoring[11]. Alveolar minute ventilation, respiratory rate and $\mathrm{CO}_{2}$ production were continuously recorded by the $\mathrm{CO}_{2} \mathrm{SMO}$ plus monitor. Representative base line carbon dioxide production in a $70 \mathrm{~kg}$ male is $200 \mathrm{ml} /$ $\mathrm{min}$. An average of a 5 minute period of these parameters was recorded before the start of CPAP as a baseline and at 1 and 2 hours during each CPAP period with the study gases. Systolic and diastolic blood pressure and heart rate were recorded directly by means of an indwelling arterial catheter and electrocardiogram (ECG) attached to a bedside monitor. Arterial partial pressure of carbon dioxide and oxygen were obtained over a 2-hour period from arterial blood gas samples.

Patients were randomly assigned to initially breath either Heliox or air-oxygen mixtures. Patients were blinded to the gas mixture they received. Data was collected directly to a laptop computer and the researcher and study statistician who analysed the data were blinded to the gas mixtures. Following baseline measurements, patients received 2 hours of CPAP ventilation (PEEP setting remained unchanged and pressure support set to zero) with helium-oxygen or air-oxygen via an eVent ventilator (eVent Medical Inc. 81 Columbia Suite 101, Aliso Viejo, CA 92656). This ventilator was calibrated for the helium oxygen mixture on an individual patient basis according to the manufacturer's instructions. Patients were returned to their pre study ventilator settings for 2 hours, before being given the alternative gas mixture for 2 hours.

The level of CPAP support and $\mathrm{FiO}_{2}$ were unchanged for individual patients throughout the trial period. The study CPAP trial was defined as unsuccessful and discontinued if the patients developed two or more of the following criteria: respiratory rate $>40$ breaths $/ \mathrm{min}$ or rapid shallow breathing index $(\mathrm{RSBI})>105 ; \mathrm{SpO}_{2}<90 \%$ or $\mathrm{SpO}_{2}$ decrease to $>8 \%$ from the patients baseline value; $\mathrm{HR}>140$ beats/min or $\mathrm{HR}$ changes by $>20 \%$ from the patients baseline; systolic blood pressure $>200$ $\mathrm{mmHg}$ or $<80 \mathrm{mmHg}$ or systolic blood pressure changes by $>20 \%$ of baseline; deterioration in conscious level, defined as a fall in GCS of $>2$, or if the patient became agitated/sweating/anxious.

The data were tested for normality and a paired t-test was used to test the treatment effect on within-subject differences. A priori the 2-hour time point was used as a summary measure of treatment effect. The data were expressed as means, standard deviations (SD) and 95\% confidence intervals $(\mathrm{CI})$. A p-value of $<0.05$ was considered statistically significant.

\section{Results}

Twenty-three patients were recruited into the study. A total of 19 completed the study protocol and their baseline characteristics are displayed in Table 1. Patients were treated with mechanical ventilation for a median 
Table 1 Patient characteristics

\begin{tabular}{|c|c|c|c|c|c|c|c|}
\hline $\begin{array}{l}\text { Patient } \\
\text { number }\end{array}$ & Age & Primary reason condition & $\begin{array}{l}\text { Secondary reason } \\
\text { condition }\end{array}$ & $\begin{array}{l}\text { APACHE } \\
\text { II }\end{array}$ & $\begin{array}{c}\text { Status at } \\
\text { unit } \\
\text { discharge }\end{array}$ & $\begin{array}{l}\text { Length of unit } \\
\text { stay (rounded) }\end{array}$ & $\begin{array}{l}\text { Length mechanical } \\
\text { ventilation till } \\
\text { inclusion }\end{array}$ \\
\hline 1 & 21 & $\begin{array}{l}\text { Status epilepticus or uncontrolled } \\
\text { seizures }\end{array}$ & & 17 & Alive & 11 & 9 \\
\hline 2 & 77 & Pulmonary haemorrhage not defined & $\begin{array}{c}\text { Thoracic or thoraco- } \\
\text { abdominal aortic } \\
\text { aneurysm }\end{array}$ & 22 & Alive & 21 & 12 \\
\hline 3 & 84 & $\begin{array}{c}\text { Inhalation pneumonitis (smoke or } \\
\text { gases) }\end{array}$ & & 19 & Alive & 11 & 12 \\
\hline 4 & 44 & Pneumonia, no organism isolated & Depression & 14 & Alive & 9 & 5 \\
\hline 5 & 84 & $\begin{array}{l}\text { Haemorrhage or haematoma from } \\
\text { pelvis, long bones or joints }\end{array}$ & Fractured ribs & 23 & Alive & 30 & 12 \\
\hline 6 & 65 & Intracerebral haemorrhage & $\begin{array}{c}\text { Secondary } \\
\text { hydrocephalus }\end{array}$ & 20 & Alive & 5 & 2 \\
\hline 7 & 30 & $\begin{array}{c}\text { Traumatic rupture or laceration of } \\
\text { liver }\end{array}$ & Hypovolaemic shock & 16 & Alive & 17 & 13 \\
\hline 8 & 68 & Lung collapse or atelectasis & Lung abscess & 16 & Alive & 23 & 6 \\
\hline 9 & 46 & Primary (diffuse) brain injury & $\begin{array}{l}\text { Lumbar spine fracture } \\
\text { or ligamentous injury }\end{array}$ & 25 & Alive & 27 & 26 \\
\hline 10 & 47 & Primary (diffuse) brain injury & Amputation of limb & 15 & Alive & 10 & 6 \\
\hline 11 & 72 & Primary (diffuse) brain injury & $\begin{array}{c}\text { Traumatic subarachnoid } \\
\text { haemorrhage }\end{array}$ & 19 & Alive & 9 & 7 \\
\hline 12 & 76 & Abdominal aortic aneurysm, ruptured & $\begin{array}{c}\text { Acute renal failure due } \\
\text { to haemodynamic } \\
\text { causes }\end{array}$ & 18 & Dead & 12 & 7 \\
\hline 13 & 45 & Primary (diffuse) brain injury & $\begin{array}{l}\text { Pneumonitis due to } \\
\text { food and vomit }\end{array}$ & 10 & Alive & 13 & 10 \\
\hline 14 & 18 & Traumatic myocardial perforation & $\begin{array}{c}\text { Anoxic or ischaemic } \\
\text { coma or } \\
\text { encephalopathy }\end{array}$ & 12 & Alive & 22 & 17 \\
\hline 15 & 36 & Tracheal trauma or perforation & $\begin{array}{c}\text { Traumatic } \\
\text { pneumothorax }\end{array}$ & 19 & Alive & 20 & 12 \\
\hline 16 & 28 & Traumatic subdural haemorrhage & Focal brain injury & 9 & Alive & 10 & 8 \\
\hline 17 & 58 & $\begin{array}{c}\text { Chronic obstructive pulmonary } \\
\text { disease with acute exacerbation, } \\
\text { unspecified }\end{array}$ & & 15 & Alive & 3 & 1 \\
\hline 18 & 79 & Traumatic subdural haemorrhage & & 28 & Alive & 6 & 4 \\
\hline 19 & 67 & Pneumonia, no organism isolated & Pleural effusion & 24 & Alive & 12 & 9 \\
\hline Mean & 53.3 & & & 17.3 & & 13.9 & 9.2 \\
\hline SD & 21.7 & & & 5.0 & & 7.6 & 5.7 \\
\hline Median & & & & & & & 9 \\
\hline IQR & & & & & & & $6-12$ \\
\hline
\end{tabular}

9 days (inter-quartile range, IQR, 6-12 days). The primary underlying condition was neurological in 8 patients, medical in 4 patients, polytrauma in 6 patients with 1 surgical patient. One patient was recruited with an infective exacerbation of COPD.

Four patients did not have evaluable data and were not included in the analysis. One patient became anxious when commenced on CPAP and withdrew consent (helium-oxygen), in 2 patients the respiratory rates exceeded the protocol within 15 minutes of commencing CPAP and were returned to their pre-study ventilatory support (1 helium-oxygen, 1 air-oxygen) and
1 patient was randomised but developed epileptic seizures just prior to starting CPAP and was withdrawn. Fifteen of the patients were studied on an $\mathrm{FiO}_{2}$ of 0.3 or less, three patients were on an $\mathrm{FiO}_{2} 0.35$ and one patient on an $\mathrm{FiO}_{2}$ of 0.4. Nine patients received helium-oxygen mixture first compared to ten receiving air-oxygen first.

Compared to air-oxygen, helium-oxygen significantly decreased $\mathrm{VCO}_{2}$ production at the end of the 2 hour period of CPAP ventilation (Figure 1) There was a mean difference in $\mathrm{CO}_{2}$ production of $48.9 \mathrm{ml} / \mathrm{min}(95 \% \mathrm{CI}$ 18.7-79.2 $\mathrm{p}=0.003$ ) between the groups. There were no 


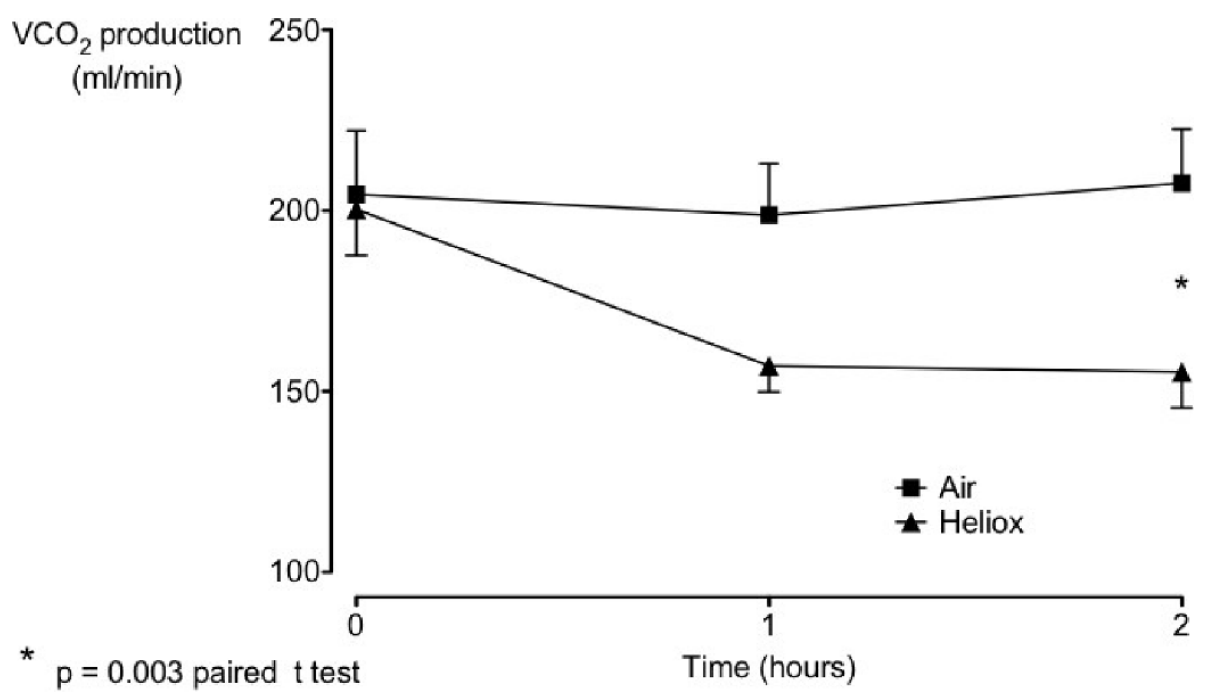

Figure 1 Carbon dioxide production over time in hours for heliox and air.

significant differences between baseline and 2 hours CPAP with air-oxygen and helium-oxygen in all other respiratory and heamodynamic parameters measured (Table 2).

\section{Discussion}

Our study showed a significant reduction in $\mathrm{CO}_{2}$ production in patients without significant airways disease. This supports the need for a definitive clinical study of Heliox in weaning from mechanical ventilation to be undertaken. We were surprised by the $19 \%$ reduction in $\mathrm{CO}_{2}$ production seen while breathing helium oxygen although this is in keeping with a $21 \%$ reduction in work of breathing shown by Diehl et al in their study [10]

Weaning from mechanical ventilation has a major impact on ICU bed occupancy and patient outcome, and has significant cost implications. Strategies to facilitate weaning have a major potential to improve patient outcome and reduce the use of healthcare resources. We demonstrate in this physiological study that patients weaning from mechanical ventilation show a significant reduction in carbon dioxide production when breathing a helium-oxygen mixture. We found that all other respiratory and cardiovascular parameters measured showed no significant changes from baseline values.

In our study we used $\mathrm{CO}_{2}$ production as a surrogate for the work of breathing. Studies have confirmed that inspiratory muscular work of breathing is proportional to the exhaled volume of $\mathrm{CO}_{2}$ per minute after allowing a period of time for stabilisation of $\mathrm{CO}_{2}$ [12-14]. Our findings are consistent with previous studies using helium-oxygen in intubated patients with COPD during controlled ventilation and on pressure support ventilation during the weaning phase of ventilation $[15,16]$. These studies have shown a reduction in total, resistive and elastic work of breathing with helium-oxygen mixtures. In spontaneously breathing patients with COPD during a T-piece trial there was a reduction in work of breathing from 1.4 to $1.1 \mathrm{~J} / \mathrm{L}$ in 13 patients with COPD and a reduction in intrinsic positive end expiratory pressure PEEPi [10]. Change in flow from turbulent to transitional or laminar by the use of the less dense helium is

Table 2 Respiratory and haemodynamic parameters during the study period

\begin{tabular}{lccccc}
\hline & Baseline & Helium/oxygen after 2 hours CPAP & Baseline & Air/oxygen after 2 hours CPAP & Statistical significance \\
\hline RR, breaths/min & $24+/-7$ & $25+/-5$ & $26+/-6$ & $25+/-6$ & $\mathrm{NS}$ \\
$\mathbf{P a C O 2}, \mathbf{k P a}$ & $5.2+/-1.0$ & $5.2+/-1.0$ & $5.4+/-1.1$ & $5.4+/-1.2$ & $\mathrm{NS}$ \\
$\mathbf{P a O 2}, \mathbf{k P a}$ & $11.3+/-2.1$ & $11.2+/-1.8$ & $12.7+/-2.3$ & $11.7+/-2.4$ & $\mathrm{NS}$ \\
Minute volume & $10.2+/-2.8$ & $10.8+/-2.5$ & $10.6+/-2.3$ & $10.2+/-2.4$ & $\mathrm{NS}$ \\
HR, beats/min & $89+/-14$ & $89+/-13$ & $88+/-14$ & $91+/-14$ & $\mathrm{NS}$ \\
SBP, $\mathbf{m m H g}$ & $128+/-27$ & $126+/-23$ & $126+/-23$ & $130+/-27$ & $\mathrm{NS}$ \\
DBP, $\mathbf{m m H g}$ & $63+/-8$ & $62+/-10$ & $63+/-11$ & $65+/-12$ & $\mathrm{NS}$ \\
Temperature & $37+/-1$ & $37+/-1$ & $37+/-1.5$ & $37+/-1$ & $\mathrm{NS}$ \\
\hline
\end{tabular}

Definitions of abbreviations; $\mathrm{RR}=$ respiratory rate; $\mathrm{HR}=$ heart rate; $\mathrm{SBP}=$ systolic blood pressure; $\mathrm{DBP}=$ diastolic blood pressure; $\mathrm{NS}=$ non significant. Values are means $+/$ - standard deviation 
thought to be a major reason for improvement in gas flow. However, a study by Papamoschou, demonstrated that helium-oxygen does not need to be laminar to improve flow and benefits exist even if flow remains turbulent [7]. In a study in 18 patients without COPD studied immediately post-extubation, helium-oxygen given for 15 minutes reduced inspiratory effort as measured by transdiaphragmatic pressure changes. A significant subjective improvement in respiratory comfort was also observed. This benefit reversed when patients were returned to air-oxygen [17]. However as patients were already weaned to the point of extubation, no conclusion can be drawn as to whether helium-oxygen improved the weaning phase. A further small study of helium use in infants post-cardiac surgery, during weaning, showed a reduction in $\mathrm{CO}_{2}$ production and an increase in $\mathrm{PaO}_{2}$ reflecting a reduction in work of breathing [9]. Our current study extends these previous data to a group of general adult intensive care unit patients without significant airways disease during the weaning phase of mechanical ventilation. While this physiological study has demonstrated a beneficial but transient effect on $\mathrm{CO}_{2}$ production with the short-term use of a helium mixture, future studies designed to investigate the effect on duration of weaning would require longer term use of helium mixture.

It is worth noting that helium can interfere with the function of ventilators and in particular, flow measurement devices. It is therefore important that clinicians are aware of the effects helium can have on the equipment they use, and equipment must be compatible with, and calibrated for, use with helium [18].

This study has several limitations. The aim of this physiological study was to measure $\mathrm{CO}_{2}$ production in patients without documented obstructive airways disease. It is not possible to exclude that a proportion of the patients had unrecognised small airways obstruction. The study is limited by the small number of patients and one patient had a documented history of COPD. Importantly when this patient is removed from the analysis the beneficial effect of helium-oxygen is still significant. In addition, we used $\mathrm{CO}_{2}$ production as a surrogate for work of breathing. Carbon Dioxide production is one of the indirect calorimetric methods of measuring metabolic rate. Factors other than work of breathing that increase metabolic rate will likely increase $\mathrm{CO}_{2}$ production. No changes to the physical workload of our patients were made during the study period. Furthermore there was no difference in other measured respiratory and haemodynamic parameters or temperature as shown in Table 2. This indirectly indicates that the change in $\mathrm{CO} 2$ production is likely to indirectly reflect work of breathing. Measurements of transoesophageal pressures or pressure-volume loop would have been useful to more directly assess work of breathing but unfortunately these were not available.

In conclusion, our study demonstrated a significant reduction in $\mathrm{CO}_{2}$ production, as a surrogate measure of work of breathing, in adult patients during the weaning phase of ventilation breathing a helium-oxygen mixture. This provides support for a clinical study powered for duration of weaning as the primary outcome to be undertaken.

\section{Abbreviations}

$\mathrm{CO}_{2}$ : carbon dioxide; COPD: chronic obstructive pulmonary disease; CPAP: continuous positives airway pressure; DBP: diastolic blood pressure; $\mathrm{FiO}_{2}$ : fraction inspired oxygen; HR: heart rate; RR: respiratory rate; NS: non significant; PEEPi: positive end expiratory pressure intrinsic; SBP: systolic blood pressure; RSBI: rapid shallow breathing index.

\section{Acknowledgements}

The authors would like to thank all the staff from the ICU who participated in this study. Dr Fiona Warburton Statistician, Joint R\&D Office Barts \& the London NHS Trust.

\section{Author details}

${ }^{1}$ Intensive Care Unit, Royal London Hospital, Whitechapel, London, E1 1BB, UK. ${ }^{2}$ Respiratory Medicine Research Immunity, The Queen's University Belfast, Northern Ireland. ${ }^{3}$ Intensive Care Unit, Prince of Wales Hospital, Barker Street, Sydney, NSW, 2031, Australia.

\section{Authors' contributions}

GF participated in the study design and set up, recruitment of patients, data collection and manuscript writing. GM, MH, MS participated in patient recruitment, data collection, review of the manuscript. DM participated in study design, coordination and set up and review of the manuscript 'All authors read and approved the final manuscript.'

\section{Competing interests}

The authors declare they have no competing interests. The Royal London Hospital received an unrestricted $£ 10,000$ grant from BOC to support this study which was used to purchase the CO2MO monitor. Two ventilators were loaned by $\mathrm{BOC}$ to the hospital for the duration of the study.

Received: 15 November 2009 Accepted: 26 August 2010

Published: 26 August 2010

\section{References}

1. Esteban A, Alia I, Ibanez J, Benito S, Tobin MJ: Modes of mechanical ventilation and weaning. A national survey of Spanish hospitals. The Spanish Lung Failure Collaborative Group. Chest 1994, 106:1188-1193.

2. Maclntyre NR, Cook DJ, Ely EW Jr, et al: Evidence-based guidelines for weaning and discontinuing ventilatory support: a collective task force facilitated by the American College of Chest Physicians; the American Association for Respiratory Care; and the American College of Critical Care Medicine. Chest 2001, 120:375S-395S.

3. Esteban A, Frutos F, Tobin MJ, et al: A comparison of four methods of weaning patients from mechanical ventilation. Spanish Lung Failure Collaborative Group. N Engl J Med 1995, 332:345-350.

4. Maclntyre NR: Evidence-based ventilator weaning and discontinuation. Respir Care 2004, 49:830-836.

5. Barach AL: Use of Helium as a New Therapeutic Gas. 1934, 462-464.

6. Otis $A B$, Bembower WC: Effect of gas density on resistance to respiratory gas flow in man. J Appl Physiol 1949, 2:300-306.

7. Papamoschou D: Theoretical validation of the respiratory benefits of helium-oxygen mixtures. Respir Physiol 1995, 99:183-190.

8. Colebourn $\mathrm{CL}$, Barber $\mathrm{V}$, Young JD: Use of helium-oxygen mixture in adult patients presenting with exacerbations of asthma and chronic obstructive pulmonary disease: a systematic review. Anaesthesia 2007, 62:34-42. 
9. Tatsuno K, Imai Y, Konno S: Therapeutic use of helium-oxygen mixture in continuous positive airway pressure for early weaning from mechanical ventilation after cardiovascular surgery in infants. J Thorac Cardiovasc Surg 1976, 72:119-122.

10. Diehl JL, Mercat A, Guerot E, et al: Helium/oxygen mixture reduces the work of breathing at the end of the weaning process in patients with severe chronic obstructive pulmonary disease. Crit Care Med 2003, 31:1415-1420.

11. Rockmann F: Evaluation of a new combined $\mathrm{CO} 2$ and respiratory monitoring system. Clinical intensive care ed 2004, 123-129.

12. Arnold JH, Thompson JE, Arnold LW: Single breath $\mathrm{CO} 2$ analysis: description and validation of a method. Crit Care Med 1996, 24:96-102.

13. Sutton PJ, Perkins CL, Giles SP, McAuley DF, Gao F: Randomised controlled cross-over comparison of continuous positive airway pressure through the Hamilton Galileo ventilator with a Drager CF 800 device. Anaesthesia 2005, 60:72-76.

14. Taskar V, John J, Larsson A, Wetterberg T, Jonson B: Dynamics of carbon dioxide elimination following ventilator resetting. Chest 1995, 108:196-202.

15. Gainnier M, Arnal JM, Gerbeaux P, Donati S, Papazian L, Sainty JM: Heliumoxygen reduces work of breathing in mechanically ventilated patients with chronic obstructive pulmonary disease. Intensive Care Med 2003, 29:1666-1670

16. Tassaux D, Gainnier M, Battisti A, Jolliet P: Helium-oxygen decreases inspiratory effort and work of breathing during pressure support in intubated patients with chronic obstructive pulmonary disease. Intensive Care Med 2005, 31:1501-1507.

17. Jaber $S$, Carlucci A, Boussarsar M, et al: Helium-oxygen in the postextubation period decreases inspiratory effort. Am J Respir Crit Care Med 2001, 164:633-637.

18. Tassaux D, Jolliet P, Thouret JM, Roeseler J, Dorne R, Chevrolet JC: Calibration of seven ICU ventilators for mechanical ventilation with helium-oxygen mixtures. Am J Respir Crit Care Med 1999, 160:22-32.

doi:10.1186/1465-9921-11-117

Cite this article as: Flynn et al:: Helium-oxygen reduces the production of carbon dioxide during weaning from mechanical ventilation.

Respiratory Research 2010 11:117.

\section{Submit your next manuscript to BioMed Central and take full advantage of:}

- Convenient online submission

- Thorough peer review

- No space constraints or color figure charges

- Immediate publication on acceptance

- Inclusion in PubMed, CAS, Scopus and Google Scholar

- Research which is freely available for redistribution

Submit your manuscript at www.biomedcentral.com/submit
Biomed Central 